\title{
Glottic impersonation, perhaps, but direct visualization remains vital to confirm successful intubation
}

\author{
James Bowness, MB, BChir, FRCA - Alasdair Taylor, MB, ChB, FRCA • \\ Hugh Gifford, BM, BCh, MA, MRCP
}

Received: 5 March 2017/Revised: 13 March 2017/Accepted: 18 April 2017/Published online: 25 April 2017

(C) Canadian Anesthesiologists' Society 2017

\section{To the Editor,}

We read, with interest, the article from Kovacs et al. ${ }^{1}$ highlighting the potentially confusing appearance of the pharyngoesophageal region. The striking resemblance of the esophageal opening to the vocal cords, with even some rings of tracheal cartilage seen distally, is certainly a potential issue that if acted upon could lead to significant morbidity and even mortality.

It should be noted, however, that the published image does contain a readily identifiable larynx anteriorly, complete with arytenoid/corniculate cartilages and vocal cords. We suggest that it does not demonstrate a singularly dangerous "glottic impersonation," as both glottic and esophageal structures are present and the laryngotracheal structures are known to be situated anteriorly. Nevertheless, such an appearance could lead to esophageal intubation when the larynx cannot be visualized, particularly by inexperienced or infrequent intubators. Although even novice laryngoscopists must be aware of the relative positions of the larynx/trachea and the pharynx/esophagus, teaching should clearly emphasize the potential visual similarity during zealous laryngoscopy (which may occur during the high stress of emergency airway management, as the authors suggest).

The bands at the lateral walls of the pharyngoesophageal junction could be from the known constriction produced by the cricopharyngeal part of the inferior pharyngeal

This letter is accompanied by a reply. Please see Can J Anesth 2017; 64: this issue.

J. Bowness, MB, BChir, FRCA $(\bowtie)$.

A. Taylor, MB, ChB, FRCA .

H. Gifford, BM, BCh, MA, MRCP

Department of Anaesthesia, Ninewells Hospital, Dundee, UK

e-mail: james.bowness@nhs.net constrictor. However, one cannot exclude the possibility of its appearance as artefactual, possibly as a consequence of the cadaveric embalming processes used in the authors' report. This would require further study in living subjects.

As the authors stated, direct visualization should not be used in isolation. In the United Kingdom and Canada, waveform capnography is an essential part of routine monitoring during anesthesia. ${ }^{2,3}$ Alone, however, it serves as the gold standard for ventilation of the lungs. ${ }^{4}$ We have had the experience of an endotracheal tube (ETT) that was seen passing between the vocal cords, but a capnography trace was not obtained, leading to repeat intubation. Profound bronchospasm rendered this patient difficult to ventilate, with waveform capnography verifying ETT placement only when the bronchospasm resolved (as has been recognized in the literature). ${ }^{4}$ In this situation and during equipment failure or a delay in side stream capnography, direct visualization is superior for confirming intubation. Bronchoscopic confirmation, as the authors also suggested, may not be suitable in the emergency setting.

Therefore, we maintain our belief that visualizing the ETT passing between the cords is superior for confirming the ETT position and has not been usurped by waveform capnography. To minimize delay and maximize sensitivity in recognizing ETT malposition, however, we advocate utilizing both of these techniques in conjunction with clinical assessment of ventilation.

Conflicts of interest The authors declare no sources of funding ot commercial or non-commercial affiliations that are or may be perceived to be a conflict of interest.

Editorial responsibility This submission was handled by Dr. Hilary P. Grocott, Editor-in-Chief, Canadian Journal of Anesthesia. 


\section{References}

1. Kovacs $G$, Duggan $L V$, Brindley $P G$. Glottic impersonation. Can. J Anesth 2017; 64: 320.

2. Checketts MR, Alladi R, Ferguson K, et al. Recommendations for standards of monitoring during anaesthesia and recovery 2015: Association of Anaesthetists of Great Britain and Ireland. Anaesthesia 2016; 71: 85-93.
3. Dobson G, Chong M, Chow L, et al. Guidelines to the practice of anesthesia - revised edition 2017. Can J Anesth 2017; 64: 65-91.

4. Frerk C, Mitchell VS, McNarry AF, et al. Difficult Airway Society 2015 guidelines for management of unanticipated difficult intubation in adults. Br J Anaesth 2015; 115: 827-48. 